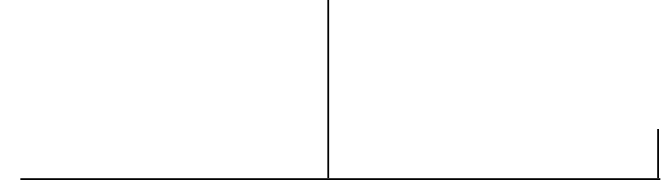

Rev. Latinoam. Psicopat. Fund., São Paulo, v. 11, n. 2, p. 301-309, junho 2008

\title{
Pierre Janet e os atos psíquicos inconscientes revelados pelo automatismo psíquico das histéricas
}

Mário Eduardo Costa Pereira

Pierre Janet constrói uma obra de grande prestígio e repercussão no campo da psicologia e da psicopatologia. Baseada na hipótese de que o psiquismo não é em si mesmo unitário, mantendo-se integrado pela ação de uma força interna de síntese de seus diversos elementos ideativos e afetivos, sua teoria psicopatológica examina os fatores que podem conduzir a sua ruptura e conseqüente dissociação. A histeria constitui, aos olhos do cientista francês, o protótipo mesmo da situação psicopatológica em que elementos que deveriam permanecer "inconscientes", ou seja, como meros panos de fundo do funcionamento mental, adquirem autonomia e acesso mórbido à consciência do sujeito.

Palavras-chave: Janet, psicologia, automatismo psíquico, inconsciente, histeria 
Em seu "Estudo autobiográfico", de 1925, Freud reconhece que as obras de Janet antecipavam alguns dos resultados que ele próprio e Breuer haviam - antes e independentemente do cientista francês - encontrado pelo emprego do método catártico em pacientes histéricas. Este risco da perda da primazia em descrever os fenômenos inconscientes à base da histeria teria sido um dos argumentos que finalmente teriam feito Breuer decidir-se por aceitar a publicação de suas descobertas na "Comunicação preliminar", de 1893, ou seja, mais de uma década após o término do tratamento de Anna O. Entre esses resultados obtidos por Janet, Freud menciona explicitamente "o rastreamento de sintomas histéricos em fatos da vida do paciente e sua eliminação por meio da reprodução hipnótica" (Freud, 1925, p. 33). Em sua tese de filosofia, apresentada em 1889, Janet chegara mesmo a sustentar que fenômenos mentais inconscientes estariam à base dos estranhos sintomas de clivagem da personalidade observados na histeria. Freud acompanhava atento e sobressaltado os avanços do pensamento de Janet, pois este parecia estar na mesma via que conduzira às descobertas dos dois médicos vienenses. $\mathrm{Na}$ carta a Fliess, datada de 10 de março de 1898, por exemplo, Freud faz o seguinte relato a seu amigo: "Recentemente, abri um livro publicado por Janet, Hystérie et idées fixes, com o coração batendo descompassado, e tornei a colocá-lo de lado com a pulsação tranqüila. Ele não tem a mínima idéia da chave". Janet era, pois, uma ameaça que merecia ser vigiada, mesmo que permanecesse longe dos elementos centrais da teoria freudiana.

Dessa forma, desde os primórdios da psicanálise, uma intensa e apaixonada questão sobre a natureza de mecanismos inconscientes subjacentes aos estados neuróticos, sobre a nova proposta de tratamento psicológico de tais fenômenos, bem como sobre o mérito dessas descobertas, oporia esses dois grandes nomes da história da 
psicopatologia: Freud e Janet. Mas como, afinal, a obra de Janet aproxima-se e se distancia tanto do inconsciente dinâmico proposto por Freud?

Em sua monumental Histoire de la découverte de l'inconscient (1970), Henri Ellenberger sustenta que Pierre Janet teria sido o primeiro, cronologicamente, a propor um novo sistema de psiquiatria dinâmica destinado a substituir aqueles do século XIX, herdeiros das teorias sobre o magnetismo animal, das descobertas dos hipnotizadores, da sugestão, dos combates entre as tradições iluministas e românticas e, finalmente, do tratamento moral.

Janet nasceu em Paris, no ano de 1859. Oriundo de uma família católica de classe média, o jovem Pierre decide-se desde cedo orientar-se para o estudo da filosofia, realizando estudos brilhantes. Seu tio, Paul Janet, professor de filosofia na Sorbonne, exerceria grande influência em sua formação.

Foi admitido em 1879 na prestigiosa École Normale Supérieure na mesma turma de Durckheim, um ano depois de Bergson, com quem desenvolveria um forte vínculo de amizade e de trocas intelectuais que se estenderiam ao longo de toda sua vida. Em 1882, Janet obtém sua agregação em filosofia, sendo em seguida nomeado professor em Châteauroux. Naquele mesmo ano, Charcot pronuncia uma histórica conferência na Académie des sciences "... reabilitando oficialmente a hipnose, a qual subitamente adquire um estatuto científico" (Ellenberger, 1994, p. 359). Era uma época em que a pesquisa sobre a histeria e sobre a hipnose interessavam não apenas aos especialistas, mas ao conjunto dos intelectuais e homens de ciência.

Em 1883, Janet passa a lecionar filosofia no liceu do Havre, o que lhe dá a oportunidade de freqüentar os Serviços de psiquiatria dos doutores Gilbert e Powilewicz, motivado pelo projeto de realizar uma tese de doutorado sobre as relações entre as alucinações e os mecanismos de percepção. É nesse momento que passa a estudar de forma sistemática os fenômenos do sonambulismo, dos transes hipnóticos e das personalidades múltiplas. Encontra, assim, suas primeiras pacientes, como Léonie, Marie-Rose e Lucie, cujas histórias clínicas seriam por ele descritas e comentadas em estudos que se tornariam célebres. Seus primeiros trabalhos tratariam justamente daquilo que Janet considerava como "formas inferiores da vida mental": catalepsia, sonambulismo, sonhos, hábito, instintos e paixões (cf. Nicolas, 2003, p. 7). Esse é o ponto de partida para a elaboração de sua teoria do automatismo psicológico, criada originalmente para dar conta dos fenômenos amnésicos observados nos quadros histéricos de desdobramentos da personalidade.

Em novembro de 1885, Paul Janet apresenta diante da Sociedade de Psicologia Fisiológica de Paris o relato do caso Léonie, elaborado por seu sobrinho Pierre. Esse caso, que entraria para a história dos estudos sobre as relações entre 
histeria e hipnotismo, era o de uma mulher susceptível de ser hipnotizada à distância e que, sob tal condição, manifestava capacidades de clarividência e de sugestão mental. $\mathrm{O}$ trabalho causou profunda impressão em um célebre participante da reunião: Jean-Martin Charcot.

Em junho de 1889, Janet defende sua tese de filosofia sobre o automatismo psicológico, conceito por meio do qual pretendia elucidar os estranhos estados mentais observados na histeria, no sonambulismo e na catalepsia. Nesse trabalho, o jovem pesquisador sustentava que os estados histéricos de desdobramento da consciência - tão intrigantes do ponto de vista sintomatológico - decorreriam de "idéias fixas inconscientes", oriundas de acontecimentos traumáticos. Os ataques histéricos, de acordo com sua teoria, seriam a reprodução automática de tais vivências, invadindo de maneira autônoma a personalidade do paciente. Sua noção de "automatismo psicológico" diferia, contudo, daquela de "automatismo mental" proposta anos mais tarde por Clérambault, uma vez que para Janet tratava-se de um fenômeno intrínseco à consciência, à história pessoal e ao quadro psicológico do indivíduo, ao passo que para o segundo, o automatismo irromperia inesperadamente no campo do eu, como fenômeno estrangeiro ao sujeito e ao qual o psiquismo deveria adaptar-se ou reagir.

Segundo a teoria proposta por Janet, a personalidade seria constituída de uma instância "que conserva as organizações do passado" e de outra "que sintetiza e organiza os fenômenos presentes". Tais instâncias, em condições normais, funcionariam de forma harmônica e integrada. Contudo, determinadas situações mórbidas, notadamente as manifestações histéricas de tipo amnésico e/ou anestésico, bem como os estados de personalidades múltiplas ou dissociadas colocariam em evidência a disjunção entre diferentes instâncias do psiquismo, com estreitamento temporário do campo da consciência, decorrente de uma diminuição na capacidade de síntese, a qual deveria dar ao eu sua aparência de unidade coerente. Evidencia-se, assim, a existência de uma seconde conscience, subjacente ao pensamento normal e composta de lembranças, representações, imagens e sensações, que seria capaz ainda de determinar o comportamento a despeito da consciência imediata do sujeito. Em sua tese, Janet qualificaria tais processos mentais de "inconscientes", em um sentido mais descritivo do que propriamente dinâmico, como o fará Freud: “... entende-se por ato inconsciente uma ação tendo todas as características de um fato psicológico menos uma, que ela é ignorada pela pessoa que a executa no momento mesmo que esta a executa" (Janet, 1889, p. 8). É somente mais tarde, com a difusão das hipóteses de Freud e Breuer, elaboradas em paralelo com as descobertas de Janet, que este viria a considerar tais fenômenos definitivamente como "subconscientes", embora esse termo já ocupasse um lugar de destaque em seu estudo sobre o automatismo psicológico. 
A repercussão de sua tese de filosofia é imediata, conferindo a Janet grande notoriedade e prestígio. Em novembro de 1889, Janet inicia em Paris seus estudos de medicina, passando a freqüentar os serviços de Jules Falret, de Séglas e de Charcot. Este cria, para Janet, o Laboratório de Psicologia Experimental da Salpêtrière. Passa a dedicar-se, então, à investigação sistemática dos processos mentais observados na histeria. Dessa forma, em 1893, diante de uma banca da qual participavam Charcot e Richet, apresenta sua tese de medicina intitulada $O$ estado mental das histéricas (estigmas e acidentes mentais). Nela, Janet sustenta uma concepção psicológica da psicopatologia da histeria, o que o levaria a propor que o tratamento dessa afecção poderia ser feito pelos meios psicoterapêuticos.

Janet interpretava as perturbações histéricas como expressões de um estreitamento do campo de consciência ou como uma clivagem da personalidade decorrente da emergência de estados hipnóides. Sob tais condições, a personalidade perde sua coesão interna e certos aspectos passariam a funcionar de maneira autônoma e separada do restante do psiquismo. Fenômenos como as alucinações, delírios, obsessões e desdobramentos do eu seriam decorrentes desse fracasso na capacidade de síntese do psiquismo, rompendo-se a arquitetura intrapsíquica habitual e permitindo a emergência de uma atividade mental ordinariamente inconsciente, ou, mais precisamente, tratar-se-ia do aparecimento de certas formas de consciência que normalmente deveriam permanecer subjacentes à consciência normal, como uma espécie de pano de fundo imperceptível. São o traumatismo e a fraqueza herdada da capacidade de síntese psíquica os fatores que permitiram que tais elementos mentais passassem a ocupar um papel tão proeminente nos estados psicopatológicos.

Sua teoria centrava-se nas noções de tensão e de força psicológicas. Dessa forma, Janet considera que a unidade do eu é garantida pela capacidade de síntese mental. Sua noção de "fraqueza psicológica" é de natureza fundamentalmente psíquica. Em condições normais, as chamadas "formas inferiores da vida mental" encontram-se presentes no indivíduo, embora submetidas ao controle de sua livre vontade. Em condições mórbidas, que enfraqueçam essa capacidade de submeter tais elementos a um funcionamento unitário do eu, ocorre uma clivagem da personalidade, com dissociação da consciência e manifestação automática daquelas formas primitivas do funcionamento mental. Trata-se, portanto, de um mecanismo de base econômica segundo o qual o enfraquecimento da capacidade de síntese expõe o eu a ser passivamente invadido por elementos mentais que deveriam manter-se afastados e submetidos ao restante do psiquismo. Para Janet, portanto, todas as funções mentais e todas as lembranças de eventos passados "são integradas em uma personalidade unificada e dominada pelo 'eu', cujo 
traço central é a consciência da identidade pessoal" (Nicolas, 2003, p. 10). É o fracasso na capacidade da síntese psíquica, ocasionado pela ação de traumas psíquicos agindo sobre uma personalidade predisposta por uma hereditariedade marcada pela degenerescência, que conduz ao aparecimento dos fenômenos psicopatológicos da dissociação psíquica.

Já em seu artigo de 1894, intitulado "As neuropsicoses de defesa", Freud esclareceria as diferenças fundamentais entre seu ponto de vista e aquele sustentado por Janet:

De acordo com a teoria de Janet (1892-4 e 1893), a divisão da consciência é um traço primário da modificação mental na histeria. É baseada em uma fraqueza inata da capacidade de sínteses psíquicas, na estreiteza do "campo da consciência" (champ de la conscience), que na forma de um estigma psíquico, evidencia a degeneração dos indivíduos histéricos. (p. 54)

Freud mostrará, a seguir, que o caráter inovador de sua própria teoria, construída em colaboração com Breuer, consistia no fato de que a divisão da consciência é por ele considerada como secundária e adquirida. Acrescenta, de forma contundente, que esta ocorre por um ato de vontade que implica uma tomada de posição efetiva por parte do sujeito: “... a divisão do conteúdo da consciência resulta de um ato voluntário do paciente; ou seja, é iniciado por um esforço de vontade cujo motivo pode ser especificado" (Freud, 1894, p. 58-9). Tal motivo é explicado em termos de uma defesa do sujeito contra a emergência de um estado afetivo insuportável: “... uma ocorrência de incompatibilidade na sua vida ideativa - isto é, (...) seu eu foi confrontado com uma experiência, uma idéia ou um sentimento que suscitavam um afeto tão aflitivo que o sujeito decidia esquecê-lo..." (ibid., p. 59). Não se trataria, pois, de um acontecimento passivo, decorrente de um enfraquecimento relativo da capacidade sintética do eu, mas de um ímpeto (o substantivo Drang alemão - força, ímpeto - inscreve-se no próprio conceito freudiano central de "recalcamento": Ver-dräng-ung) com que o sujeito visa ativamente se opor à emergência de uma condição mental insuportável.

Do ponto de vista terapêutico, Janet propunha o uso da hipnose e da sugestão para obter um efeito catártico das idéias e representações separadas da personalidade em função de traumas e de vivências pessoais não suficientemente elaboradas. Nesse contexto, sua proposta de uma "análise psicológica" sistemática, realizada em um contexto de intimidade com o paciente, com atenção rigorosa nas palavras efetivamente pronunciadas e buscando restituir detalhadamente os antecedentes pessoais e a história da doença, constituía ao mesmo tempo um elemento importante da pesquisa psicopatológica e uma dimensão decisiva para a instituição da terapêutica psicológica. 
Gozando de grande reputação no campo da nascente psicologia francesa, Janet é nomeado, em 1897, catedrático de Psicologia Experimental na Sorbonne. Cinco anos mais tarde, em 1902, contando com o decisivo apoio de Bergson, Janet é nomeado para a vaga deixada por Théodule Ribot junto ao Collège de France, vencendo eleição na qual tinha por adversário Alfred Binet. Passa, então, a realizar uma grande síntese de suas teorias, sendo De l'angoisse à l'extase, livro publicado em 1926, uma primeira tentativa de sistematização do conjunto de suas idéias.

Em 1913, durante o Congresso Internacional de Medicina, realizado em Londres, ocorre o episódio maior do longo desentendimento entre Janet e Freud. Naquela ocasião, realiza uma crítica incomumente severa e injusta contra a teoria freudiana, denunciando-a como uma mera apropriação desnaturada de suas próprias idéias. A intervenção de Janet foi muito malrecebida pela platéia, a qual já conhecia com certa profundidade e respeito a especificidade da teoria freudiana, provocando assim péssima repercussão internacional e assinalando uma espécie de turning point em direção ao declínio de seu prestígio.

O legado de Janet nos campos da análise psicológica, da teoria psicopatológica da histeria e de outros estados, como a "psicastenia" e a angústia, e da abordagem psicoterapêutica das neuroses é da maior importância, influenciando diretamente toda uma geração de psicólogos e psicopatólogos pela interrogação do papel do eu, e de sua unidade apenas aparente, na constituição da personalidade e de suas perturbações.

\section{Referências}

Ellenberger, H. Histoire de la découverte de l'inconscient. Paris: Fayard, 1994.

Freud, S. (1894). As neuropsicoses de defesa. In: Edição Standard Brasileira das Obras Psicológicas Completas de Sigmund Freud. São Paulo, Imago, 1976. v. III, p. 55-73.

. (1925). Um estudo autobiográfico. In: Edição Standard Brasileira das Obras Psicológicas Completas de Sigmund Freud. São Paulo, Imago, 1976. v. XX, p. 17-92. . A correspondência completa de Sigmund Freud para Wilhelm Fliess 18871904 (Editor J. Masson). Rio de Janeiro: Imago, 1986.

Hart, O. Ian Hacking on Pierre Janet: Observations. Dissociation, v. 9, n. 1, p. 80-84, 1996.

JANET, P. (1889). L'automatisme psychologique. Essai de psychologie expérimentale sur 
les formes inférieures de l'activité humaine. Paris: Félix Alcan (Reimpresso pela Société Pierre Janet, Paris, 1973).

. (1892). Conférences à la Salpêtrière: anesthésie, amnésie et suggestion chez lês hystériques. Paris: L'Harmattan, 2003.

. (1926). De l'angoisse à l'extase. Paris: Félix Alcan, 1975. v. I e II.

Nicolas, S. Introduction de l'éditeur. In: JANET, P. (1892). Conférences à la Salpêtriè$r e$ : anesthésie, amnésie et suggestion chez lês hystériques. Paris: L'Harmattan, 2003. p. 7-13.

Postel, J. La psychiatrie. Paris: Larousse, 1994.

Postel, J. \& Quetel, C. Nouvelle histoire de la psychiatrie. Toulouse: Privat, 1983.

Roudinesco, E. \& Plon, M. Dicionário de psicanálise. Rio de Janeiro: Jorge Zahar, 1998.

\section{Resumos}

(Pierre Janet y los actos psíquicos inconcientes desvelados por el automatismo psíquico de las histericas)

Pierre Janet construye una obra de gran prestigio y repercusión en el campo de la psicología y de la psicopatología. Basada en la hipótesis de que el psiquismo no es en sí mismo unitario, manteniéndose integrado por la acción de una fuerza interna de síntesis de sus diversos elementos ideativos y afectivos, su teoría psicopatológica examina los factores que puedan conducir a su ruptura y consecuente disociación. La histeria constituye, a los ojos del científico francés, el prototipo mismo de la situación psicopatológica en que elementos que deberían permanecer "inconcientes", o sea, como mero telón de fondo del funcionamiento mental, adquieren autonomía y acceso mórbido a la conciencia del sujeto.

Palabras clave: Janet, psicología, automatismo psíquico, inconciente, histeria

(Pierre Janet et les actes psychiques inconscients relevés par l'automatisme psychique des hystériques)

Pierre Janet a construit une oeuvre de grand prestige et répercussion sur le champ de la psychologie et de la psychopathologie. Fondée sur l'hypothèse selon laquelle le psychisme n'est pas unitaire, mais qu'il reste intégré par l'action d'une force interne de synthèse des différents éléments idéatifs et affectifs, sa théorie psychopathologique porte sur les facteurs capables de produire la rupture et, par conséquent, la dissociation du fonctionnement mental. L'hystérie constitue à ses yeux le prototype même de la situation psychopathologique dans laquelle des éléments 


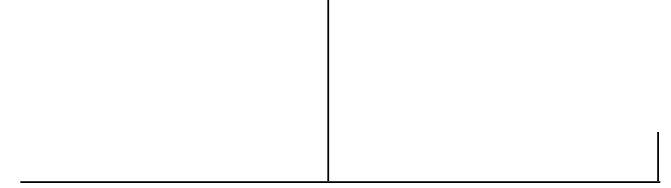

mentaux qui devraient rester "inconscients", c'est-à-dire, comme simple fond du fonctionnement psychique, deviennent autonomes et, par là, ils ont accès morbide à la conscience du sujet.

Mots clés: Janet, psychologie, automatisme psychique, inconscient, hystérie

(Pierre Janet and unconscious psychic acts revealed by the psychic automatism of hysterical patients)

Pierre Janet wrote works of great prestige and repercussion in the field of psychology and psychopathology. His theory of psychopathology is based on the hypothesis that the mental apparatus is not really a unit. It is rather held together by the action of an internal force that synthesizes its diverse cognitive and emotional elements. In his article Janet examines factors that can lead to the breakdown and consequent dissociation of this apparatus. In his view, hysteria is a true prototype of the psychopathological situation where elements that should remain "unconscious," that is, that should serve as mere background for mental functioning, acquire autonomous and morbid access to the consciousness of the subject.

Key words: Janet, psychology, psychic automatism, unconscious, hysteria

Versão inicial recebida maio de 2008 Versão aprovada para publicação em maio de 2008

\section{Mário Eduardo Costa Pereira}

Psiquiatra; psicanalista e professor do Depto. de Psicologia Médica e Psiquiatria da Universidade Estadual de Campinas - Unicamp (Campinas, SP, Brasil); doutor em Psicopatologia Fundamental e Psicanálise pela Universidade Paris 7 (Paris, França); diretor do Laboratório de Psicopatologia Fundamental da Unicamp; professor do Departamento de Psicanálise do Instituto Sedes Sapientiae (São Paulo, SP, Brasil); membro da Associação Universitária de Pesquisa em Psicopatologia Fundamental (São Paulo, SP, Brasil); autor dos livros Pânico e desamparo (São Paulo: Escuta, 1999) e Psicopatologia dos ataques de pânico (São Paulo: Escuta, 2003).

Rua Carolina Prado Penteado, 725 - Nova Campinas

13092-470 Campinas, SP, Brasil

Fone: (19) 3254-5064 / 3254-1982 / 3289-4819 (Unicamp)

e-mail: marioecpereira@uol.com.br

Rev. Latinoam. Psicopat. Fund., São Paulo, v. 11, n. 2, p. 301-309, junho 2008 